\title{
Polymer Membranes as a Reaction Field I. A Characterization of Environment of Polymer
}

\author{
Takeo SHIMIDZU* and Masakazu YoshIKAwA \\ Department of Hydrocarbon Chemistry, Faculty of Engineering, \\ Kyoto University, Kyoto 606, Japan
}

(Received August 31, 1982)

\begin{abstract}
The environment of a polymer field as a solid medium could be evaluated using a spiropyran compound as an indicator. This method provides a useful means for an accurate determination of polymer character.

KEY WORDS Synthetic Polymer Membrane / Polymer Reaction Field / Spiropyran Derivative / Photochromism / Dimroth's Solvent Polarity Value / Characterization of Polymer /
\end{abstract}

Hitherto synthetic polymer membranes have been used as barriers for separating two phases and media for selective separation. Recently, the latter has been studied by the introduction of a carrier to promote its capability for these functions. Synthetic polymer membranes having chemical functional groups function as selective separation membranes. The active and selective transport of metal ions with synthetic membranes such as a lactone-containing polymer membrane was demonstrated for the first time. $^{1-5} \mathrm{Up}$ to now, anion transport membranes have been developed by Ogata and his coworkers. ${ }^{6}$

The synthetic membrane can also be used to provide the reaction field with the function so as to separate or concentrate the product from a reaction mixture. This is of interest in connection with polymer catalysts.

The authors synthesized a novel spiropyran derivative having a long alkyl group, 1-octadecyl-3,3dimethyl-6'-nitrospiro(indoline-2, $2^{\prime}-2 H$-benzopyran) (1), and found that the active transport (symport) of a salt across the anisotropic liquid membrane could be brought about by light illumination using the photochromism of $1 .^{7}$ The authors also reported the possibility of salt permeation rate control by light with the blended membrane obtained by the introduction of $\mathbf{1}$ into a synthetic polymer membrane. ${ }^{8}$ The photochromic process of $\mathbf{1}$ is as follows:

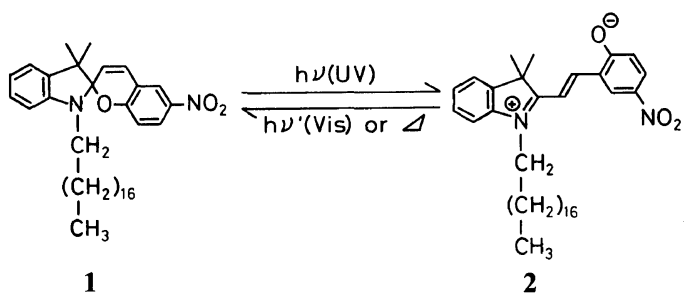

A plot of the wavelength of the absorption maximum of the chromophore, 2, formed by the ringopening of 1 in various solution in the visible range $\left(\lambda_{\max }^{\text {Vis }}\right)$ vs. Dimroth's solvent polarity value $\left(E_{\mathrm{T}}\right.$ $\left(25^{\circ} \mathrm{C}\right)$ ) gave a straight line. ${ }^{7}$ The measurement of $\lambda_{\max }^{\mathrm{Vis}}$ of 2 , which is the ring-opened form of $\mathbf{1}$ introduced into a synthetic polymer, makes it possible to evaluate the character of a synthetic polymer as a chemical reaction medium. Here, the authors investigate the characrerization of the environment of the membrane as a part of the study on the utilization of synthetic polymer membranes for a reaction field. Spiropyran compounds were found to be useful indicators because of their photoreactions.

\section{EXPERIMENTAL}

\section{Materials}

1-Octadecyl-3,3-dimethyl-6'-nitrospiro(indoline$2,2^{\prime}-2 H$-benzopyran) (1) was synthesized as described previously. ${ }^{7}$ 1,3,3-Trimethyl-6'-nitrospiro- 
(indoline-2,2'-2H-benzopyran) (3) was purchased from Tokyo Kasei Kogyo Co., Ltd. Among the polymer samples, polyethylene (PE) and poly(vinyl acetate) (PVAC) were provided at the courtesy of the Central Research Laboratory of Sumitomo Chemical Co., Ltd. Polystyrene (PST), poly(vinyl chloride) (PVC), poly(methyl methacrylate) (PMMA), and cellulose acetate (acetyl content, $55 \%$ ) (CA) were purchased from commercial sources. Polymethacrylonitrile (PMAN) and polyacrylonitrile (PAN) were prepared by ordinary radical polymerization (bulk polymerization) initiated by $2,2^{\prime}$-azobisisobutyronitrile. The solvents for polymers, ethyl acetate (EtAc), $N, N$-dimethylformamide (DMF), and acetone, were purified in the usual manner.

\section{Membrane Preparation}

A casting solution was made by dissolving $1 \mathrm{~g}$ of a polymer and $10 \mathrm{mg}$ of $1(5 \mathrm{mg}$ of 3$)$ in $10 \mathrm{~cm}^{3}$ of a solvent. The solution was poured in a UV cell, allowing the solvent to evaporate at ambient temperature. For the PE membrane, the indicator was mixed with PE by shattering with a ball mill. The PE membrane was then prepared by the melt method.

\section{Illumination}

A $500 \mathrm{~W}$ xenon lamp was used as the light source. The membrane was illuminated with UV light using a Corning color filter No. 7-54.

\section{Spectroscopic Measurement}

Absorption spectra were measured with a Union Giken SM-302 spectrophotometer.

\section{RESULTS AND DISCUSSION}

$\lambda_{\max }^{\mathrm{Vis}}$ 's of $\mathbf{2}$ in common polymers are summarized in Table II. $E_{\mathrm{T}}\left(25^{\circ} \mathrm{C}\right)$ 's were calculated using the relationship ${ }^{7}$ between $E_{\mathrm{T}}\left(25^{\circ} \mathrm{C}\right)$ and $\lambda_{\max }^{\mathrm{Vis}}$, and also are summarized in Table II. It became apparent that the polarity of the polymer membrane used in the present study was between tetrachloromethane and methanol on comparison of the obtained value with small molecules.

The dipole-dipole interactions, $\delta_{\mathrm{p}}$, which are among th components contributing to the solubility parameter, were used as parameters reflecting polymer polarity. In Figure $1, \lambda_{\max }^{\mathrm{Vis}}$ of 2 is plotted

Table I. Casting solution solvents

\begin{tabular}{ll}
\hline Polymer & Solvent \\
\hline PST & EtAc \\
PE & - \\
PVC & DMF \\
PMMA & Acetone \\
PVAC & Acetone \\
CA & Acetone \\
PMAN & Acetone \\
PAN & DMF \\
\hline
\end{tabular}

a PE membrane was prepared by the melt method.

Table II. $\quad \lambda_{\max }^{\text {Vis }}$ and Dimroth's solvent polarity values $\left(E_{\mathbf{T}}\left(25^{\circ} \mathrm{C}\right)\right)$ of polymers

\begin{tabular}{|c|c|c|c|c|}
\hline \multirow{3}{*}{ Polymer } & \multicolumn{2}{|c|}{1} & \multicolumn{2}{|c|}{3} \\
\hline & $\lambda_{\max }^{\mathrm{Vis}}$ & $E_{\mathrm{T}}\left(25^{\circ} \mathrm{C}\right)^{\mathrm{a}}$ & $\lambda_{\max }^{\mathrm{Vis}}$ & $E_{\mathrm{T}}\left(25^{\circ} \mathrm{C}\right)^{\mathrm{b}}$ \\
\hline & $\mathrm{nm}$ & $\mathrm{kcal} \mathrm{mol}^{-1}$ & $\mathrm{~nm}$ & $\mathrm{kcal} \mathrm{mol}^{-1}$ \\
\hline PST & 603 & 31.7 & 603 & 30.3 \\
\hline $\mathrm{PE}$ & 580 & 40.3 & - & - \\
\hline PVC & 578 & 41.0 & 580 & 37.9 \\
\hline PMMA & 574 & 42.5 & 570 & 41.2 \\
\hline PVAC & 566 & 45.5 & 563 & 43.5 \\
\hline $\mathrm{CA}$ & 560 & 47.7 & 554 & 46.4 \\
\hline PMAN & 555 & 49.6 & 558 & 45.1 \\
\hline PAN & 540 & 55.1 & 545 & 49.4 \\
\hline
\end{tabular}

a $E_{\mathrm{T}}=\left(688.3-\lambda_{\max }^{\mathrm{Vis}}\right) / 2.69$.

b $E_{\mathrm{T}}=\left(695.2-\lambda_{\max }^{\mathrm{Vis}}\right) / 3.04$. 


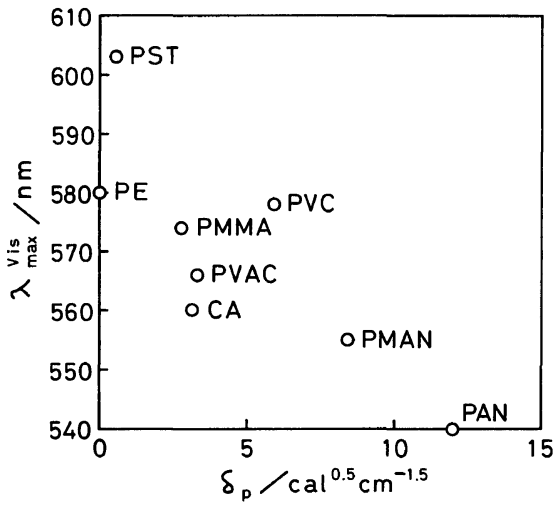

Figure 1. Relationship between $\delta_{\mathrm{p}}$ and $\lambda_{\max }^{\mathrm{Vis}}$ of $\mathbf{2}$.

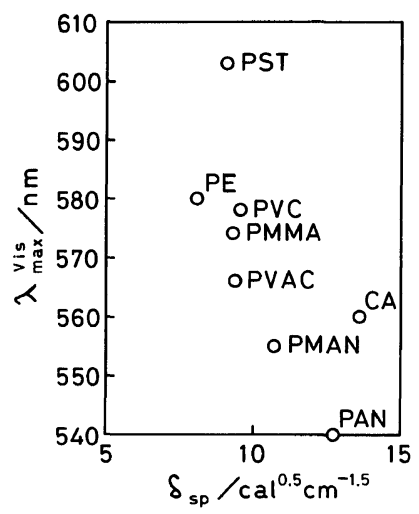

Figure 2. Relationship between $\delta_{\text {sp }}$ and $\lambda_{\max }^{\text {vis }}$ of 2 .

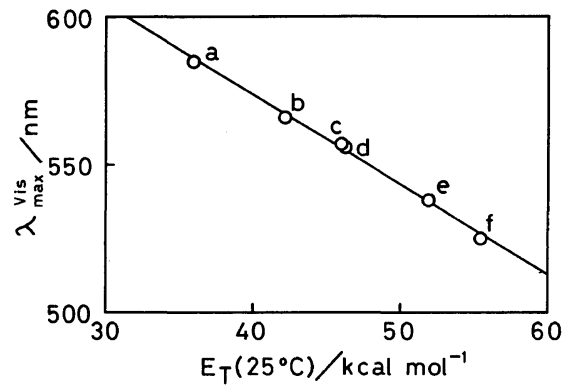

Figure 3. Relationship between Dimroth's solvent polarity value $\left(E_{\mathrm{T}}\left(25^{\circ} \mathrm{C}\right)\right)$ and $\lambda_{\max }^{\mathrm{Vis}}$ of 4 : a, 1,4-dioxane; b, acetone; c, acetonitrile; d, nitromethane; e, ethanol; f, methanol.

against $\delta_{\mathrm{p}}{ }^{9}$ The plot of $\lambda_{\max }^{\mathrm{Vis}} \nu s . \delta_{\mathrm{p}}$ did not give a straight line since $\delta_{\mathrm{p}}$ is a parameter concerned with only one physical property. But hypsochromic shift of $\lambda_{\max }^{\text {Vis }}$ corresponded to the increase in the $\delta_{\mathrm{p}}$ values.

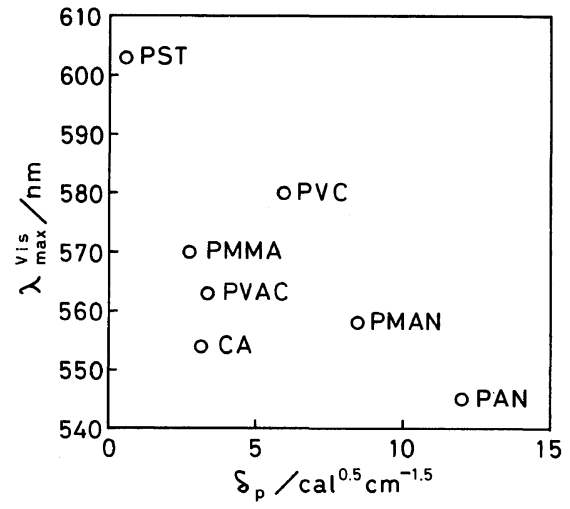

Figure 4. Relationship between $\delta_{\mathrm{p}}$ and $\lambda_{\max }^{\mathrm{Vis}}$ of 4.

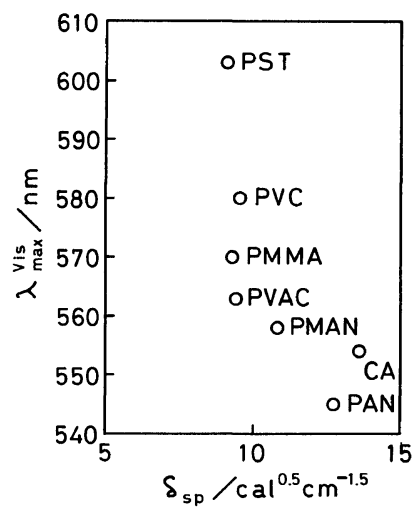

Figure 5. Relationship between $\delta_{\mathrm{sp}}$ and $\lambda_{\max }^{\mathrm{V}_{\text {is }}}$ of 4.

$\lambda_{\max }^{\text {Vis }}$ is plotted as a function of the solubility parameter, ${ }^{10} \delta_{\mathrm{sp}}$, in Figure 2. The plot of $\lambda_{\max }^{\mathrm{Vis}} v s . \delta_{\mathrm{sp}}$ did not give a straight line because $\delta_{\mathrm{sp}}$ arises from three physical properties; hydrogen bonding, permanent-dipole-permanent-dipole interactions, and the London dispersion force.

In Figure 3, $\lambda_{\max }^{\text {Vis }}$ of the chromophore, 4, formed by the ring-opening of 3 in various solutions is plotted against $E_{\mathrm{T}}\left(25^{\circ} \mathrm{C}\right)$. A good straight line relationship was observed similar to that in the case of 2.

In Figure $4, \lambda_{\max }^{\mathrm{Vis}}$ is plotted against $\delta_{\mathrm{p}}$ with $\mathbf{4}$ as the indicator. $\lambda_{\max }^{\text {Vis }}$ showed a hypsochromic shift with increasing values for $\delta_{\mathrm{p}}$, as shown in Figure 1. Also, the absorption spectrum of 4 in PE membrane was too broad to allow for identification.

The plot of $\lambda_{\max }^{\mathrm{Vis}} v s$. $\delta_{\mathrm{sp}}$ is shown in Figure 5. The tendency for $\lambda_{\max }^{\text {vis }}$ to shift hypsochromically with increase in $\delta_{\mathrm{sp}}$ values was observed. 
$\lambda_{\max }^{\text {Vis }}$ 's of 4 in common polymers and $E_{\mathrm{T}}\left(25^{\circ} \mathrm{C}\right)$ values calculated from Figure 3 are summarized in Table II along with the results obtained by using 2 as an indicator. Nearly the same $E_{\mathrm{T}}\left(25^{\circ} \mathrm{C}\right)$ value was obtained for either spiropyran. This suggests that the spiropyran compound may be used as an indicator. But $E_{\mathrm{T}}\left(25^{\circ} \mathrm{C}\right)$ values obtained with 4 , which has three methyl groups as alkyl substituents, tended to be smaller than those obtained with $\mathbf{2}$, which has one octadecyl group as an alkyl substituent instead of a methyl group. That is, the apparent polarity of the polymer membrane obtained with $\mathbf{4}$ tended to be lower than that obtained with 2 . The locations of the spiropyrans in the polymer matrix probably differ from each other. The spiropyran derivative with a long alkyl group, $\mathbf{1}$ or 2 , has greater compatibility toward polymers than 3 or 4 . This may be attributed to the difference in the contribution toward the interaction between the indicator and the polymer of the coulombic force, dispersion force, charge transfer, hydrogen bonding, etc.

It became apparent during the course of this work that the environment of a polymer field as a solid medium can be evaluated using a spiropyran compound as the indicator. The present study, in a certain sense, is concerned with the photoreaction of a spiropyran in the polymer. Also the photochromism of the spiropyran may be used as a convenient indicator. Our results thus indicate that spiropyrans may be used for the characterization of not only polymer membranes but also polymer matrices. This simple method is thus a useful means for the determination of polymer character, particularly that of membrane materials.

Acknowledgement. The authors are deeply grateful to the Central Research Laboratory of Sumitomo Chemical Co., Ltd. for kindly providing some of the standard polymer samples.

\section{REFERENCES AND NOTES}

1. T. Shimidzu, M. Yoshikawa, and M. Hasegawa, IARC Reports, 3, 7 (1977).

2. T. Shimidzu, M. Yoshikawa, M. Hasegawa, and H. Chiba, Kobunshi Ronbunshu, 34, 753 (1977).

3. T. Shimidzu, M. Yoshikawa, and K. Kawakatsu, Polym. J., 12, 363 (1980).

4. T. Shimidzu, M. Yoshikawa, M. Hasegawa, and K. Kawakatsu, Macromolecules, 14, 170 (1981).

5. T. Shimidzu, M. Yoshikawa, and B. Ohtani, Macromolecules, 14, 506 (1981).

6. N. Ogata, K. Sanui, H. Tanaka, H. Fujimura, Y. Kawachi, Kobunshi Ronbunshu, 38, 583 (1981).

7. T. Shimidzu and M. Yoshikawa, J. Membrane Sci., in press.

8. T. Shimadzu and M. Yoshikawa, Polym. J., to be submitted.

9. $\delta_{\mathrm{p}}$ values were calculated by reference to the text [T. Matsuura, "Gōseimaku no Kiso," Kitami Shobō, Tokyo, 1981, pp 25-31].

10. H. Burrel, "Polymer Handbook," 2nd ed, J. Brandrup and E. H. Immergut, Ed., John Wiley \& Sons, New York, 1975, pp IV-355-IV-358. 